\title{
Loin Pain and Haematuria Syndrome (LPHS) Complicating Symptomatic Nephroptosis (SN), Cured with Renal Sympathetic Denervation and Nephropexy (RSD\&N) Surgery: Case Report
}

\author{
${ }^{1}$ Consultant Urologist Surgeon, Egypt \\ ${ }^{2}$ Mansoura University Hospital, Egypt \\ ${ }^{3}$ North Middlesex University Hospital, London \\ ${ }^{4}$ Royal London Hospital, London
}

Ahmed N Ghanem ${ }^{1 *}$, Khalid A Ghanem² ${ }^{2}$ Nisha Pindoria ${ }^{3}$ and Salma A Ghanem ${ }^{4}$

Received: October 30, 2018; Published: November 30, 2018

*Corresponding author: Ahmed N Ghanem, MD, FRCS, Consultant Urologist Surgeon, No1 President Mubarak Street, Mansoura 35511, Egypt

\begin{abstract}
Introduction and objective: To report a case demonstrating the link of LPHS with SN is that is based on IVU7 sign and retrograde pyelography. Renal Sympathetic denervation and Nephropexy (RSD\&N) Surgery has proved curable for the condition.

Patient and methods: The reported case in which IVU with erect film shows the IVU7 sign is measure of renal pedicle stretch. Retrograde pyelography (RGP) showed the internal renal damage while all ancillary imaging was normal. The surgery of RSD\&N was used for treatment of the condition.

Results: An IVU with erect film and RGP detected the diagnosis and the renal pathology while no other imaging could. Comparing IVU supine and erect revealed the IVU7 sign which is a measure of renal pedicle stretch causing artery stenosis and ischaemia. The findings on RGP show erosion of renal papillae and leakage of contrast medium into renal veins which is the site of hamaturia. The surgery of RSD\&N cured the condition.
\end{abstract}

Conclusion: An IVU with erect film and RGP clinched the diagnosis and revealed the renal pathology while no other imaging could. It should be essential diagnostic investigation in every LPHS case. The surgery of RSD\&N cured the condition.

\section{Introduction}

The link of SN with LPHS is a new discovery explaining its real patho-etiology [1,2]. Although SN is known for centuries, it was disparaged $>70$ years ago and omitted from all textbooks. Standard imaging protocol is constantly normal- at supine posture. Intravenous urography with erect film (IVU-E) has been

Case Report made obsolete and is not requested, hence chance diagnosis of SN is unlikely, and diagnosis is easily missed. Many of SN features and some complications were documented $>70$ years ago [3], but it was disparaged soon afterwards [4]. The LPHS was reported in 19675. Here we report an illustrative case report showing the link of LPHS with SN.

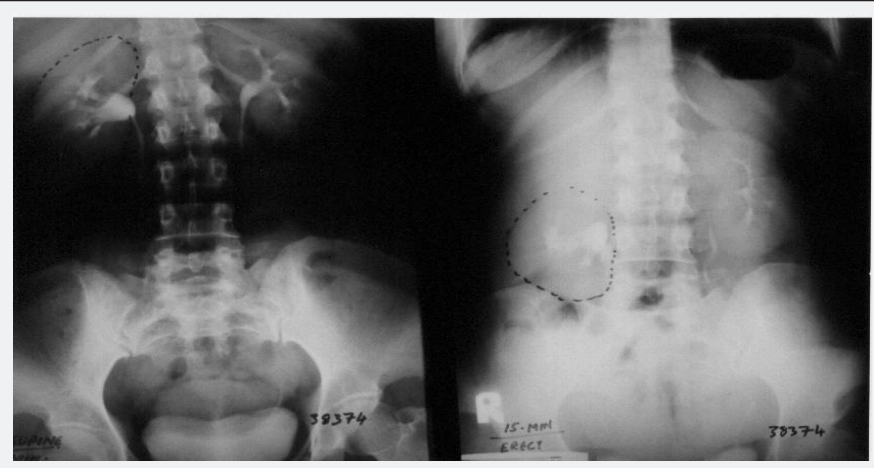

Figure 1: shows a supine compared to IVY erect film demonstrating right nephroptosis. 


\section{Open Access Journal of Surgery}

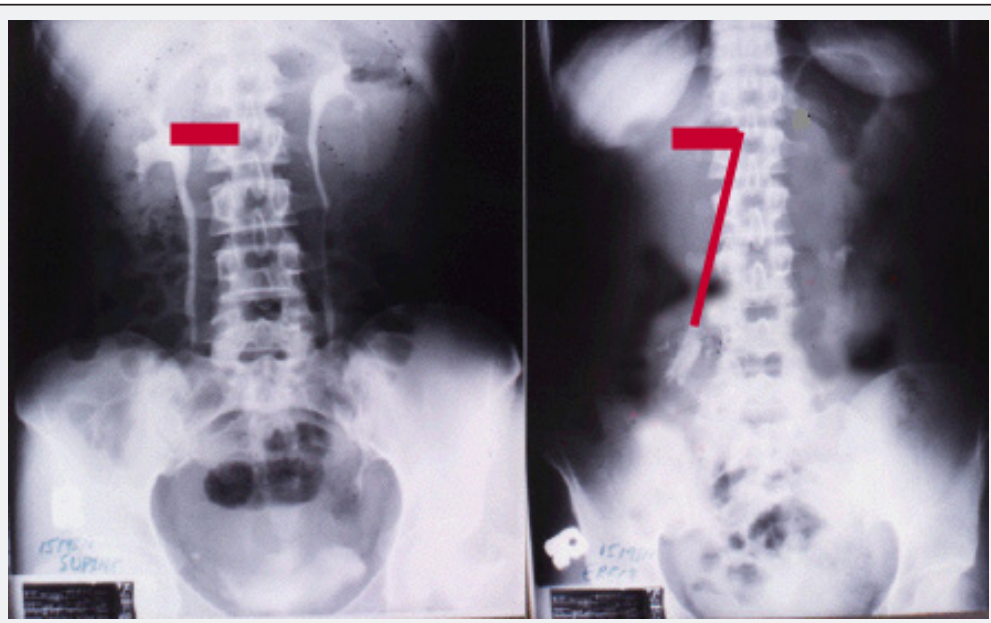

Figure 2: Shows renal pedicle mapped on a supine IVU film (Horizontal) and erect film (Vertical) limbs of 7 where the renal pedicle is stretched to 3 times its normal length, causing stenosis and ischemia.

A 28 years old girl was regularly admitted via Accident and Emergency department with severe loin pain and gross haematuria over a period of 3 years. Her repeated investigations including urine culture, IVU and CT scan were all normal when done at supine posture. An IVU-E was later done and demonstrated her overlooked SN (Figure 1). The internal renal damage explaining haematuria was revealed by the IVU7 sign (Figure 2) and on retrograde pyelography (RGP) (Figure 3). She consented for surgery and open renal sympathetic denervation and nephropexy (RSD \& N) was performed on her right kidney. She was cured of both LPHS and SN.

\section{Discussion}

The presented case report clearly demonstrates the LPHS complicates SN. The renal damage is caused by pedicle stretch causing renal ischaemia as shown on IVU7 sign (Figure 2). The internal renal damage causing pain and haematuria is best shown on RGP (Figure 3). Unfortunately, no other investigation including CT and MRI can reveal the pathology of LPHS complicating SN. Upright IVU is currently undone and has not been reported previously in LPHS. Retrograde pyelography findings (Figure 3) have not previously been documented in either condition. The use of IVU started early in the $20^{\text {th }}$ century while clinical evidence on the genuineness of SN pain dated back to the $15^{\text {th }}$ century. Loin pain hematuria syndrome was reported in 1967 [5] while Dietl's crisis is known for centuries. Organic reno-vascular complications demonstrated on conventional arteriography of SN and LPHS are of advanced cases. In view of the new evidence presented here and previously $[1,2]$, the authorities should reconsider SN with link to LPHS and bring it back to current textbooks.

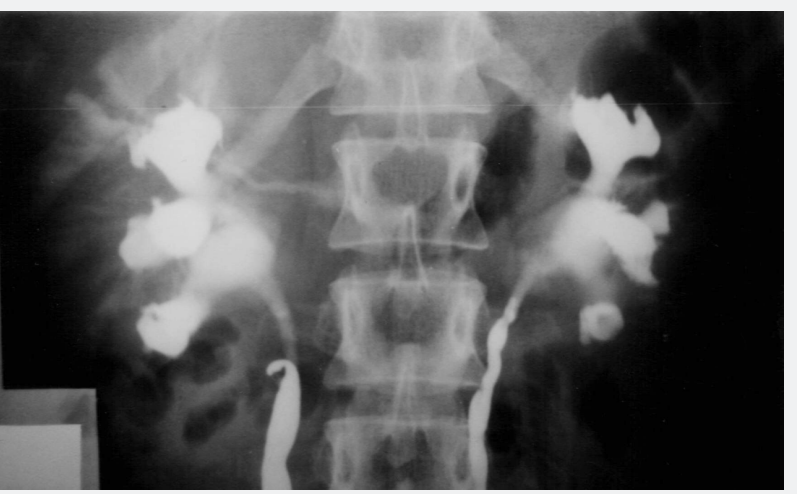

Figure 3: Shows retrograde pyelography showing erosion of renal papillae and contrast extravasations into renal veins of right kidney where haematuria occurs in an opposite direction.

\section{References}

1. Ghanem AN (2002) Features and complications of symptomatic nephroptosis causing the loin pain haematuria syndrome: Preliminary report. Saudi Med J 23(2): 197-205.

2. Ghanem SA, Ghanem AN (2016) Prospective Observational Study on Loin Pain Hematuria Syndrome Complicating Symptomatic Nephroptosis and the Results of Renal Sympathetic denervation and Nephropexy Surgery. Jacobs Journal of Nephrology and Urology 3(1): 025 .
3. Burford CE (1946) Nephroptosis with coexisting renal lesions. J Urol 55: 220-224.

4. Hoenig DM, Hemal AK, Shalhav AL, Clayman RV (1999) Nephroptosis: A "disparaged" condition revisited. Urology 54(4): 590-596.

5. Little PJ, Sloper JS, de Wardner HE (1967) A syndrome of loin pain haematuria associated with disease of the peripheral renal arteries. $Q$ J Med 36(142): 253-259. 
(C) (i) This work is licensed under Creative Commons Attribution 4.0 Licens DOI: 10.19080/OAJS.2018.10.555779
- Quality Editorial service

- Swift Peer Review

- Reprints availability

- E-prints Service

- Manuscript Podcast for convenient understanding

- Global attainment for your research

- Manuscript accessibility in different formats

( Pdf, E-pub, Full Text, Audio)

- Unceasing customer service

Track the below URL for one-step submission https://juniperpublishers.com/online-submission.php 